\title{
Symbolism in V. Woolf's "Orlando" (Cognitive Tools of Figurative Thought)
}

\author{
Natalya Davidko \\ Correspondence: Natalya Davidko, Department of International Business Management, Moscow Institute TOURO, \\ 20 PodsosenskyPereulok, Moscow 105062, Russian Federation.
}

Received: August 5, 2019

Accepted: November 20, 2019

Online Published: December 23, 2019

doi:10.5430/elr.v8n4p27

URL: https://doi.org/10.5430/elr.v8n4p27

\begin{abstract}
The current research is devoted to the study of the oak tree symbolism in V. Woolf's "Orlando" (1928) with the dual purpose of defining its functional role in the literary text and educing cognitive and cultural foundations underlying conception and development of the symbol. The principles and tools employed for the analysis allow of tracing the formation of the symbolic domain of the Tree concept to the Proto-Indo-European period. Later accretions of symbolic meanings conditioned by a mythic and religious vision of the world produced a rich paradigm of symbolic attributes grounded in the primordial archetype and adapted to a new ideology. The in-depth research into textural peculiarities and semantic content of the discourses with the oak tree as a central leitmotif reveals "prominence" choices of attributes and intricate combination thereof.
\end{abstract}

Keywords: symbol, archetype, oak, tree of life, tree of knowledge, world axis, myth, religion, gestalt, attributes, foregrounding

Grau, teurer Freund, istalleTheorie

Und grim des Lebensgoldner Baum ${ }^{1}$

(Johann Wolfgang von Goethe, 1973: 509 -514)

\section{Introduction}

Symbolic systems, being indispensable elements of any culture, are found in painting, architecture, music, politics, ideology, and many other areas of human activity. In literature, symbolism is a special rhetoric technique that helps the writer to 'present' a concept too abstract or obscure for direct sensory representation, that can be expressed only "by analogy and by the transference of reflection" (Kant, 1951: 198). A literary symbol may be a material thing, a natural element, a person, or an action that is loaded with meaning much deeper than springs to the eye, and interpretation of symbols calls for a broad cultural outlook and the aptitude to see below the surface.

Symbol formation is a process of cultural conceptualizations of the physical world through the lens of a society's contemporary world view. Symbolic meaning is a combination of knowledge, intuition, and imagination, a fusion of purely denotative and expressive functions of language, which makes it worthy of an in-depth research.

The choice of the author is not accidental. V. Woolf's prose is full of symbols suggestive of hidden messages. This aesthetic device has attracted many researchers, but the most comprehensive analysis of V. Woolf's symbolism is presented by N.C. Thakur in his seminal work where he treats symbols as a technique, worked out "for projecting the psychological conditions and inner workings of the mind of literary characters under particular circumstances" (Thakur, 1965: 197). However, few critics appear to have been interested in studying symbolic imagery in literary texts in relation to cognitive mechanisms that led to the emergence of these symbols and preconditioned their figurative usage. I can cite only the work by Dennis Young (1986), who exposes mythical, religious and philosophical roots, with the emphasis on the Eastern thought, of the androgynous character (Bernard) as a symbol of perfection and wholeness of the eternal in Nature.

The aim of the current article is to look into the specificity of the oak-tree symbol, analyze its cognitive history and its functions in V. Woolf's novel "Orlando".

\footnotetext{
1 All theory is gray, my friend. But forever green is the tree of life.
} 


\section{Theoretical Background}

The current research is carried out within the framework of Archetypal literary criticism, a doctrine that interprets a text by focusing on myths, symbols and archetypes used by the author in a particular narrative. The theory emerged in the 1930s as a fusion of Frazer's social anthropology (Frazer, 1890) and Jungian psychology (Jung, 1964) and was first applied to the analysis of literary works by Maud Bodkin in her ground-breaking book of 1934 where she gives a sweeping picture of archetypal patterns in drama and poetry from Vigil and Dante to Shakespeare, to Blake, to D.H. Lawrence and V. Woolf (Bodkin, 1934). The theory was later recast by the Canadian mythologist Northrop Frye with regard to literature (Frye, 1957) but has never been widely practiced, though many literary critics recourse to it without acknowledging it explicitly. The corner stone of this comprehensive theory of literary criticism is the Archetype, understood as deep-seated primordial images recurring beneath the surface of literary texts providing instantaneous comprehension without resorting to logic.

One important advantage of Archetypal literary criticism is that it takes a holistic view of the relationship between myths, symbols, archetypes and art including literature. The great artist, according to Jung, is a person who possesses the "primordial vision" - a special sensitivity to archetypal patterns and a gift for speaking in primordial images that enable him or her to transmit experiences of the "inner world" through art (Guerin et al., 2005: 203-204). Frye postulates the existence in some works of an archetypal symbol (a key symbol) which is dropped into the texture of work and like a magnet attracts other images becoming a unifying center for forming a conceptual unity and making it a phase of imaginative experience (Frye, 1952: 18). Archetypes function across cultures and time: it means that there are symbols that evoke similar associations in people within the same culture or different cultures at various historical periods or throughout entire human existence including pre-historical times. A symbol is then both ahistorical and part of a cultural-historical context.

\section{Methods and Objectives}

In the current research, a philological comparative method is used in studying symbolism. Philological approach includes literary criticism, history, and linguistics. Diachronic literary criticism embraces studies of written and oral texts considering them a result of human cognition adapted to a particular superstructure of culture. By a systematic comparison of related and unrelated cultures, we aim to establish a common core of symbolic attributes that make up the archetypal substratum for multiple variations. Etymological analysis is supposed to take us as far back as Proto-Indo-European period and reconstruct the concept's original structure and meaning(s), the source of future symbolic significations.

This method is complemented by two methods from Gestalt psychology introduced by the Danish gestalt psychologist Rubin (1958). The "Prominence view" which explains why, when we look at an object in our environment, we single out this or that figure as perceptually prominent. This principle has been applied to the study of language within the framework of Cognitive Linguistics (Langacker, 1991) and will be applied in our research to the study of symbolic components. The second method is called the "Attentional view," which means that we express those parts of an event which attract our attention. This is important when we analyze why a writer foregrounds some aspects of a phenomenon and keeps others in the background. We propose to apply this method to the textual analysis of "Orlando".

\section{The Concept of the Symbol}

\section{Definition}

The most common definition of the symbol is "a thing that represents or stands for something else, especially a material object representing something abstract" (CED). Researchers insist that the ability to produce symbols is the sole prerogative of human beings who can "bestow meaning upon things and events in the external world, and comprehend such meanings" (White \& Dillingham, 1973:1). For example, animal symbolism originated at an early stage of human development from totemism and animal worship when animals were endowed with the ability to signify some transcendent ideas on the basis of their distinguishing features. Thus, turtle-doves symbolize devoted love because they form strong pair bonds (Cirlot, 1971: 354). W. Goethe and C. Jung stress that symbols' function is to explicate "something vague, unknown, or hidden from us" (Jung, 1964: 21) or "reveal the inscrutable" (Goethe, 1973: 471) drawing on some familiar object in our everyday life.

Kant and Jung refer symbols to the area of the unconscious. Kant defines the symbol as a form of hypotyposis ${ }^{l}$ a rhetorical mode involving presentation or illustration; he postulates that Symbol is an Idea of imagination which is

\footnotetext{
${ }^{1} \mathrm{~A}$ vivid, picturesque description of scenes or events.
} 
greater than the mere concept of rational thinking and understanding. It induces much thought, "yet without the possibility of forming any definite concept adequate to it," and a symbol cannot be made completely intelligible by language. It is within the scope of creative imagination that "unbounded expansion" of the concept is possible, an extension of thought that exceeds what can be clearly expressed by logic (Kant, 1951: 175-177).

The Kantian ideas were carried on and developed by Susanne Langer, who holds that symbols come into play when logical reasoning and sensory experience are helpless: symbols are interpolated in the "gaps and confusions of direct experience" (Langer, 1954: 22). The very emergence of symbols and their endurance throughout ages becomes possible because they meet the basic need of man to get material for mind's new conceptualizations, hence the symbol-generating function of brain is one of man's primary activities, with the symbol being an instrument of thought (ibid.: 32).

The Symbol differs from the Archetype though they are sometimes used interchangeably. Etymologically, the word symbol is traced to the Greek symbolon 'token,' morphologically divided into syn- 'together' + bole 'a throwing together' (ED). In a symbol, fundamental relation of form and content is intrinsically based on the conventional meaning and additional specific connotations; "it implies something more than its obvious and immediate meaning" (Jung, 1964: 21). The term Archetype (from the Greek arche,, 'beginning', and typos, 'imprint') introduced by Jung to denote universal, archaic patterns that exist at the level of the collective unconscious and represent a "nebulous dynamic substratum" for figurative thought, which gives rise to a myriad of images and symbols that get specific expression in a culture in the form of archetypal events, figures/characters, and motifs (Jung, 1964). Archetypes are "image-guides" of patrimonial origin, whereas Symbols are innumerable mythic and mystic representations of variations on these archetypes.

Properties of symbols

Proceeding from its role in the history of intellectual development of mankind, we have every reason to suppose that the unique function of symbolism is to reveal some truths about reality. It is based upon a "precise and crystallized means of expression, highlighting the truth both external to man and within him" (Cirlot, 1971: xxxi). Symbols are vehicles of meanings, which are embodied in a multilayered semantic structure able to incorporate at least two types of significations: a direct, or literal, one capable of symbolic extension and a secondary, non-literal, meaning that is different in kind from its literal meaning. The two meanings are indelibly intertwined and actuated simultaneously forming a synthesized totality based on a vast complex of associations. This indirect meaning is the most characteristic feature of the symbol; even the most mundane objects become "freighted with hidden messages" when undergoing symbolic generalization, they acquire a capacity of carrying some enigma and mystery (Struck, 2004: 4), which renders them into means of artistic expression.

Jung distinguished between 'natural' and 'cultural' symbols. "The former represent an enormous number of variations on the essential archetypal images. In many cases they can still be traced back to their archaic roots i.e. to ideas and images that we meet in the most ancient records and in primitive societies. The latter, on the other hand, are those that have been used to express 'eternal truths,' and have gone through many transformations and a long process of conscious development, and have thus become collective images accepted by civilized societies. Such cultural symbols nevertheless retain much of their original "numinosity or spell" (Jung, 1964: 93).

Summing up the properties of symbols which make them both tools of thought and rhetoric devices, we can single out the following: 1) the Symbol is a specific form of representation having an ontological connection with its referent; 2) it develops a representational multiplicity and variability in that a symbolic object may stand for many things through a unique density of meanings (literal and figurative, allegorical, mythological, religious, philosophical, etc.); 3) it exists beyond rational experience and discursive logic and belongs to the area of the unconscious and intuitive; 4) it gives insight into opaque concepts and transmits hidden messages about the transcendent truth; 5) symbols are historically and culturally conditioned but some of them due to their exegetic power ascend to the universal and ahistorical.

\section{Tree Symbolism}

The tree is one of the most essential 'natural' symbols in human history. In many countries from time immemorial, certain trees have been revered as sacred (the oak was sacramental to the Celts; the ash sacrosanct to the Scandinavian peoples). Within mythologies of peoples living far apart, a metaphysical concept of the tree was shaped drawing on similar sensory experiences and perceptions. In Indian mythology and Buddhism, the Banyan Tree takes pride of place. Due to its ability to reproduce itself with seed, aerial roots and adventitious trunks, the tree represents eternal life. The roots of the tree reach endlessly deep, this depth is a symbol of the infinite. Even if the tree is burnt 
to the ground, "from the profound depth of its roots new sprouts appear" (Haberman, 2013: 167). The tree cannot die, it eternally renews itself thus becoming a symbol of regeneration and immortality. Under the banyan tree a wise father taught his son a lesson about the true nature of reality ${ }^{1}$, so the tree is often known as the Tree of Knowledge. Buddha is said to have achieved enlightenment beneath this tree. Consequently, the Banyan tree has become a symbol of not only ever-going physical renewal but of "infinite insight."

In the folklore of Hungarian and Siberian peoples, there is a concept of High Tree, which grows in the center of the world and is so high that it reaches the firmament and supports the sky as a pole or pillar does, so if you climb up to the top you will find at the pinnacle of the sky a door or a gate, the opening to the upper world, be it a house of god, or some kind of heaven, or simply another world (Erdész, 1984: 332). Most explicitly, the idea of the tree as a binding link between the worlds is presented in the ancient Norse myths of the god Odin who was looking for Yggdrasil, the Tree of life, to obtain wisdom. Here is the description of the tree:

"Its three great roots descend into a tripartite underworld: Hell, the land of the dead; the kingdom of the frost giants; and the underworld realm of gods where they gather every day by the sacred spring of Fate to resolve disputes. The trunk passes through Middle Earth, the realm of mortals; and its branches ascend the world of the gods. The seat of Odin is in the top branches from which he surveys 'the nine worlds covered by the tree'... Concealed within its trunk are the seed of the world's renewal, in the form of a man and woman, from whose union a new race will appear to repopulate the world" (Cook, 1974: 12).

Odin was able to gain wisdom from the tree, so Yggdrasilis described not only as the Tree of Life but also as the Tree of Wisdom.

At the mythological stage, we witness the emergence of a symbolic concept of the tree endowed (irrespective of the particular genus) with qualities that have mystic resonance. Based on sensory reality and common perceptions of this reality accompanied by cognitions, fantasies, aspirations and fallacies, a material object (a tree) is endued with a set of culturally constructed extraneous supernatural properties that form the core of values and meanings of fundamental significance - the archetype. While finding expression in myths and legends of particular cultures the most general conceptions of the Tree display a universal dispersion. Practically any part of the tree serves as a source for symbolization (see Table 1). "In its most general sense the symbolism of the tree denotes the life of the cosmos, its consistence, growth, proliferation, generative and regenerative processes. ... The tree becomes a symbol of absolute reality, that is of the center of the world" (Cirlot, 1971: 347).

\footnotetext{
${ }^{1} \mathrm{He}$ cut open a seed of the tree, and when his son saw nothing inside, explained to him that from that "nothingness" came the entire diverse world and that the finest essence of nothingness is the Self(Haberman, 2013: 167).
} 
Table 1. Symbolic meanings of the Tree Concept

\begin{tabular}{|c|c|}
\hline Physical properties & Symbolic attributes: Meanings and Interpretations \\
\hline $\begin{array}{l}\text { Place of growth: hill, } \\
\text { mountain, higher ground; } \\
\text { mountain top }\end{array}$ & $\begin{array}{l}\text { Related to ascent, attaining higher cosmic levels, consecration; energy and } \\
\text { knowledge of the divine; loftiness of spirit; axis of the universe/world and } \\
\text { the spinal column; the earth's navel, the beginning of creation; abode of } \\
\text { higher gods; intersection of the heaven and the earth. }\end{array}$ \\
\hline Roots & $\begin{array}{l}\text { anchors, gripping tightly into the Mother (Earth); a symbiotic union with the } \\
\text { earth, drawing on its energy; the beginning of everything; spiritual values } \\
\text { and beliefs; also: underworld, hell. }\end{array}$ \\
\hline Trunk & $\begin{array}{l}\text { Middle world of mortals, pillar, axis, steadfastness, constancy; security and } \\
\text { stability; primordial substance of Creation; abode of a man and woman who } \\
\text { will repopulate the world. }\end{array}$ \\
\hline Heartwood & the centermost pillar of stabilization; center core; essence of life. \\
\hline Boughs, Tree crown & $\begin{array}{l}\text { Multiplicity and diversity in a unity, irradiating forces, proliferation, } \\
\text { coverage; upward movement; spiritual growth. }\end{array}$ \\
\hline Buds & $\begin{array}{l}\text { Eternal cycle of life, renewal, life and death, immortality; a fresh start on } \\
\text { life, positive energy, good health and a bright future. }\end{array}$ \\
\hline Blossom and leaves & $\begin{array}{l}\text { the state before regeneration; things of wisdom; the goods of faith; } \\
\text { abundance; vitality of life; exuberance of youth. }\end{array}$ \\
\hline Seed & $\begin{array}{l}\text { Latent forces, mysterious potentialities; growth and fragility; the process of } \\
\text { living and dying; the whole universe in a grain of sand; posterity. Symbol of } \\
\text { Creation. }\end{array}$ \\
\hline Fruit & $\begin{array}{l}\text { Food, remedy, rejuvenation, immortality; abundance, associated with } \\
\text { goddesses of fruitfulness, plenty, fertility; beauty and sexuality; stage of } \\
\text { cosmic order; but also: a symbol of sin. }\end{array}$ \\
\hline Tree top & $\begin{array}{l}\text { Seat of the highest deity, connection with the upper world, contact with the } \\
\text { divine, commanding a far-ranging view of the world. }\end{array}$ \\
\hline Growth & Verticality, upward movement, ascension, spiritual evolution. \\
\hline Tree as a whole & $\begin{array}{l}\text { Axis of the world, pillar supporting heaven, inexhaustible life, immortality } \\
\text { (undying and unburnt), knowledge and wisdom, illumination and revelation, } \\
\text { height and ascent, binding earth and heaven together, portal to transcendent } \\
\text { truth. }\end{array}$ \\
\hline
\end{tabular}

The richness of tree symbolism was transferred to religion, especially Christianity. Parallelisms with myths are striking, however, religious tree symbolism is a system per se. The functions of life and knowledge vested in one tree in mythology are apportioned to two different paradisiacal trees setting up a new dual paradigm, or "two-tree" symbolism. In the Garden of Eden, God planted The Tree of Life and the tree of The Knowledge of good and evil (NIV, Genesis 2:9). The breech of God's law by Adam and Eve deprived people of immortality and transformed the Tree of Knowledge into an instrument of sin and death ${ }^{1}$. The mythological vision of the tree as a pillar supporting heaven is transferred in Christianity to the Cross of redemption also performing a dual function of the Tree of Life and a new axis of the world based on true faith. The relationship between the Cross and the Tree of Life is a complicated one forming a unity between life and death: "the life and death connotations of the tree symbol, which in primitive myth had been mere polarities, are unified anagogically through Christ's Cross, the true Lignum Vitae ${ }^{2}$, which is also seen as a cosmic cross, as a new world-supporting and unifying tree" (Ladner 1979: 238). In religious symbolism, the transgression of God's law by the first people had made the Tree of Life bare and dry, however it was

${ }^{1}$ At an early stage of Christianity, it was believed that the Tree of Knowledge furnished wood for the Cross of the Savior; later the Cross was linked with the Tree of Life (Ladner, 1979: 236).

${ }^{2}$ Tree of life (Lat.) 
made green again by the Cross (ibid.: 237). In Christian iconography, the canonical Tree of Life is always in bloom, the Tree of Knowledge is dry (Cirlot, 1971: 349).

The Church Fathers view the Tree of Life is a symbol of Jesus Christ. The Bible begins and ends with The Tree of Life. In Genesis, it is planted in the Garden of Eden; In Revelation, in the main street of the city:

"Then the angel showed me a river of the water of life, as clear as crystal, flowing from the throne of God and of the Lamb, down the middle of the great street of the city. On each side of the river stood the tree of life, bearing twelve crops of fruit, yielding its fruit every month. And the leaves of the tree are for the healing of the nations" (NIV, Revelation 22:2).

\section{Oak Tree Symbolism}

The oak tree, in addition to general tree symbolism, has developed a rich symbolic paradigm of its own. Like all other trees, it represents the axis mundi, but also stands for something very strong, steadfast and unbending. In the pre-Christian era, the oak was associated with the supreme god in the pantheons of mythological deities of different countries: Zeus (Hellenic Greece), Jupiter (Ancient Rome), Dagda (Celts), Perun (ancient Slavs), and Thor (early Germanic peoples). The tree was described as the 'lightning tree' because it attracted lightning and because the highest gods were lords and masters of rain, thunder, and lightning.

The oak was worshiped in many cultures, but it is most closely associated with the ancient Celts who regarded it as 'a cosmic storehouse of wisdom.' Oak groves were considered sacred places and became outdoor sanctuaries for Druids $^{1}$. Offerings from people were placed at the feet of the biggest oaks. The Proto-Celtic word for Druid is *derwo-weyd, dru-widgoing back to the Sanskrit word Duir (oak) combined with the Indo-European root *wid(know), suggests a hypothetical meaning 'the wise ones who have knowledge of the oak.' According to Irish early religious mythology, oaks were introduced to Ireland by Trefuilngid Tre-eochair ${ }^{2}$ (the Irish god), who on the day of Christ's crucifixion brought a branch on which were acorns, apples, and nuts and sowed them. It was believed to be a branch of the original Tree of Knowledge from the Garden of Eden. The oaks that grew were so great that could oversee and protect each plane below. It was said the tree could bear both acorns and red apples three times a year. The moment the last acorn fell, the first blossom of the apple appeared, symbolizing death and rebirth, but also a source of food and fodder (Stokes, 1983: 458).

The idea of oaks being suppliers of food, water, medication, housing, etc. is not confined to the Celtic culture alone. It was believed that "back in the golden age the oaks dripped honey, and men lived in peace and comfort with no shelter but their boughs" (Skinner, 1911: 192). Far away from Europe, in Mission Indians ${ }^{3}$ beliefs, Wyot, son of Night and Earth, guardian of all things, when he died poisoned by the frog jealous of his shapely legs and his soul went skyward, became the oak for the "sustenance of all people and animals and birds"(ibid.: 197).

Oaks are known to have helped the valiant and the valorous. In Medieval France, it is recorded that Jeanne d'Arc frequented the Fairy Oak of Bourlemont and prayed to its spirit, who in return, "gave her the charmed sword and banner with which she led her country-men to victory" (ibid.: 198). Oaks also offer protection to those in danger. The Norse legend has it that Thor found shelter from a violent storm under a mighty oak tree.

Oak trees are thought to represent everything that is true. The oldest oracle of Ancient Greece lived in Dodona ${ }^{4}$ under the sacred oak. Through the rustling of its leaves as they "low-whispered in the breeze," (Homer) the priests interpreted the messages of Zeus to the mortals. Legends go that Achilles and Argonauts went there to seek advice, and the prow of the Argo was made from one of the sacred oaks and directed the crew.

Despite its close affinity with paganism, the oak, due to its symbolic potential, became acceptable to the new faith, and was at the beginning regarded as the tree of Mary. Oak Tree symbolism is amply represented in Scripture. Throughout the Bible, saints and true believers are referred to as trees.

"Blessed is the man who walks not in the counsel of the wicked... He is like a tree planted by streams of water..." (NIV: Psalms 1). Those who trust in God are described as "oaks of righteousness, the planting of the Lord, that he

\footnotetext{
${ }^{1}$ Druids in ancient Celtic cultures were members of the high-ranking professional class: religious leaders, legal authorities, lorekeepers, medical professionals and political advisors.

${ }^{2}$ Triple Bearer of the Triple Key and Master of All Wisdom controls the setting and rising of the Sun.

${ }^{3}$ Native Americans who lived in Southern California and were forcibly relocated from their traditional homelands.

${ }^{4}$ A holy city of the prehistoric era located in the region of Epirus. Later the Oracle was eclipsed by that of Delphi.
} 
may be glorified" (NIV: Isaiah 61: 1-4). Many saints are known to have lived and preached under oaks: St. Bridget of Ireland abode "in the cell of an oak"; St. Augustine addressed King Ethelbert trying to convert him under the oak; angels communicated God's will beneath the oaks. The last resting place of Saints and devoted believers was in the shade of oak tree branches.

The etymology of the words 'tree' and 'oak' reveals an intricate relationship between the two entities, which goes beyond the relationship of 'species - genus' and gives insight into "mythico-religious" archetype in which future symbolic extensions are grounded. The Old English word treo, treow 'tree' meaning 'timber, wood' derived from Proto-Germanic *trewam, had cognates in Old Frisian (tre), Old Saxon (trio), Old Norse (tre), Gothic (triu) - all going back to PIE *drew-o-, a suffixed variant form of root *deru- 'be firm, solid, steadfast' with nominalized senses 'wood, tree' (ED). The Old English word for 'oak tree' is $a c$ from Proto-Germanic *aiks- of uncertain origin. It had cognates only inside the Germanic branch: Old Norse (eik), Old Saxon and Old Frisian $(e k)$, Middle Dutch (eike), Old High German (eih),. The usual Indo-European base for oak was *deru-, the same stem as for 'tree'. Likewise, in Celtic, 'oak' is derived from this Indo-European root but developed two symbolic generalizations: Proto-Celtic *derwos developed the meaning 'true, truth.' (This is not a stochastic phenomenon: in Anglo-Saxon, too, the word treow meant 'tree' and 'truth,' both derived from PIE root *deru-. The same regularity is found in Hebrew.). The Celtic duir (oak) initially meant 'door', thus signifying that The Celtic Tree of Life served as a portal to spiritual worlds, an access to sacred knowledge, and an opening/door to divinity. Thus, the primordial archetype already bears symbolic meanings: tree- truth - door. If we recall that the original meaning of truth was 'true faith,' then the symbol becomes clear: tree is the center of cosmos, a door to transcendent truth, which is true faith.

The sketchy analysis of mythology and religion shows that symbolization of conceptual content began in pre-historical time en rapport with contemporary knowledge systems and world views by binding salient properties into an integrated whole. Cognitive processing took ages if not millenniums before a holistic open-ended symbol was formed.

\section{Oak Tree Symbolism in "Orlando"}

The final part of the article is devoted to the analysis of the oak-tree symbol in V. Woolf's "Orlando". The objective is to analyze the content of various discursive situations in which the oak is the focal point and see how this content is symbolically structured and interpreted. The oak tree appears in two capacities: as a living tree and as a poem devoted to it. The two motifs are intimately interwoven in the fabric of the novel, sometimes running their individual narrative strands, sometimes melding into one.

The novel is bookended by the scenes taking place under the oak tree. At the beginning of the novel Orlando is a boy of sixteen whose favorite place in his father's vast mansion is a hill "crowned with a single oak tree. It was very high, so high indeed that nineteen English counties could be seen beneath; and on clear days thirty or perhaps forty, if the weather was very fine." (Orlando: 7). Orlando enjoyed spending time in the deep shadow of its umbrageous boughs and surveying the big picture from his own "top of the world." Symbols used in this passage are a combination of 'Mountain top' and 'singleness' The former signifies a place where mind is "open to any influence of the sky and dominating a vast landscape of earth commanding the survey of the whole extent of earthly things....Mountain top has become the accepted symbol of the true essence of life" (Bodkin, 1934: 145). The latter correlates with the religious concept of "oneness" signifying the primal energy from which all things spring, the borderline between good and evil, pursuit of truth and justice, and the unflinching devotion to one's cause. Probably, it is this energy that Orlando feels and absorbs while leaning against the hard trunk and the roots which run deep into the soil, anchoring the tree in "here and now."

"He sighed profoundly, and flung himself ... on the earth at the foot of the oak tree. He loved, beneath all this summer transiency, to feel the earth's spine beneath him; for such he took the hard root of the oak tree to be." (Orlando: 8)

One more meaningful symbol used here is that of 'spine'. Semantically, the word spine among other things, signifies 'the axis of the skeleton' and 'the heart-wood of trees' (CED). In English, 'spine' is linked with courage: the expression 'no spine' is about cowardly people. The axis-spine symbol evokes a parallel with axis mundi, which, as we have shown above, in myths, lore, and beliefs, means the world center, the world's point of beginning. In Orlando's microcosm, the oak tree on the hill marked the beginning of his adult life and his birth s a poet.

The oak awakens the boy's imagination: “...image followed image, it was the back of a great horse that he was riding, or the deck of a tumbling ship - it was anything indeed, so long as it was hard, for he felt the need of something which he could attach his floating heart to; To the oak tree he tied it" (Orlando: 8). The images that flash through the 
boy's mind are all related to dashing movement, tempestuous seas, and peril awaiting him. Among this whirl, the hardness of oak roots means an anchor of stability. He needed something sure and steadfast to cling to.

The final passage of the novel almost literally repeats the opening scene with the essential distinction that now Orlando is a woman, wife and mother, and an acclaimed poet.

"The ferny path led, with many turns and windings, higher and higher to the oak tree, which stood on the top. The tree had grown bigger, sturdier, and more knotted since she had known it, somewhere about the year 1588, but it was still in the prime of life. The little sharply frilled leaves were still fluttering thickly on its branches. Flinging herself on the ground, she felt the bones of the tree running out like ribs from a spine this way and that beneath her. She liked to think that she was riding the back of the world. She liked to attach herself to something hard" (Orlando: 160).

The scene may be interpreted as 'home coming'. V. Woolf resorts to personification, the oak tree is described in terms of the human body (spine, ribs, bones), that means it is depicted as a human being embracing the returning son/daughter. Though Orlando returns as a confident, self-possessed woman, her aspirations finally fulfilled, she still needs stability, firmness, and assurance that is emanated by the oak.

Since it is a final, closing scene, and has special significance, it seems viable at this point to briefly outline the main features of the form of an ending V. Woolf' forged to express "a final harmony" of the unfamiliar tune (Woolf 1984: 254) and which she used in the majority of her novels. V. Woolf "perceived that the moments of meaning at the ends of her novels must be placed in the wider context of a vital but unfathomable cosmos. ... At the ends of her novels, Woolf affirms life over death, the power of recovery over the power of pain, the continuity of the species and of civilization" (Beattie 1986: 522). The focal point of her endings is the suggestion of ongoing life.

The ending in "Orlando" is the triumph over death which in this particular case is symbolized by a big wave in the form of an arch.

"There was her husband's brig, rising to the top of the wave! Up, it went, and up and up. The white arch of a thousand deaths rose before it. ... But the brig was through the arch and out on the other side; it was safe at last!" (Orlando: 161).

Standing by the oak tree, she called her husband's name. This is the last "moment of meaning" related to the oak tree, the final wish-fulfilling act of bringing back Orlando's husband, resolving the central tension of her married life. It is noteworthy that the oak tree is always described in full green foliage, and never as a dry winter tree.

Between these two novel-framing scenes there is an interlude, an intermediate episode, with the oak tree acting as a safety haven, last resort in the stormy tumult of Orlando's emotions and feelings. At the age of thirty, Orlando was going through the worst crisis in his life. A rejected lover and ridiculed poet, an exile and recluse, he felt betrayed and "quit of vast mountain of illusion." He came to the oak tree every day to find peace with himself and protection for the quick of his naked soul.

"When he reached that high mound whence on fine days half of England with a slice of Wales and Scotland thrown in can be seen, he flung himself under his favourite oak tree and felt ... he might make out what years remained to him in tolerable content. Here he came then, day after day, week after week, month after month, year after year. He saw how the oak tree had put forth its leaves and shaken them to the ground a dozen times in the process" (Orlando: 47).

The scene contains a new pattern of symbolic conceptualizations, among which the most important are life cycle, death and rebirth, spiritual resurrection and reconciliation, consolation and strength drawn from communing with the oak and nature. Orlando understands one important thing: amid this turbulence there is an element of permanence and constancy when some "things remain much as they are for two or three hundred years or so" (ibid.: 48).

Here beneath the tree, he gave a solemn oath concerning his writing: never to write anything to please the public, or other poets, or critics, but to please solely himself. The passage highlights one more symbolic dimension of the oak, as old as the tree itself - eternal Truth.

"He may seek the truth and speak it; he alone is free; he alone is truthful; he alone is at peace And so he sank into a quiet mood, under the oak tree, the hardness of whose roots, exposed above the ground, seemed to him rather comfortable than otherwise." (Orlando: 50)

The discourses analyzed are examples of V. Woolf's unique technique which she herself called "Moments of being," by which she understood those moments when an individual becomes fully conscious of himself and catches a glimpse of his connection to the essence of life hidden behind "a kind of nondescript cotton wool" of daily life, the 
moments which are opening up a way to new understanding (Woolf, 1985: 70). Such moments awaken in one "a shock-receiving capacity" and an ability to become aware of previously overlooked things (ibid.: 72). Such moments brought to Orlando something eternal, which took him/her one step up spiritual ascent. The moments of revelation in the novel are explicated with the help of oak-tree symbolism, for each such moment the author chooses a symbolic attribute that most adequately resonates with the general ambiance of the situation.

The second narrative strand of the plot related to the oak tree is the poem which Orlando started to write in his early youth and continued to write and rewrite all his/her life and which was the most cherished thing that accompanied Orlando in his/her travels across time and space. When he was disillusioned with life and literature "he burnt in a great conflagration fifty-seven poetical works, only retaining 'The Oak Tree', which was his boyish dream and very short" (Orlando: 46). I think a most touching passage in the book is the one describing how amidst all bustle, reveling and feasting, Orlando, who when he needs a bit of peace and quiet, goes to his private room and takes out the poem.

"There when the door was shut, and he was certain of privacy, he would have out an old writing book, stitched together with silk stolen from his mother's workbox, and labelled in a round schoolboy hand, 'The Oak Tree, A Poem"” (Orlando: 54).

The author does not reveal the contents of the poem, not a hint or a clue is given. It was changed many times and retained very little from the original version.

“... as he scratched out as many lines as he wrote in, the sum of them was often, at the end of the year, rather less than at the beginning, and it looked as if in the process of writing the poem would be completely unwritten. In one day he would add "a line or two with enormous labour to 'The Oak Tree, A Poem"' (Orlando: 54).

When Orlando became a woman, she carried her manuscripts about with her in the bosom of her dress. Due to this poem, Orlando got recognition as a poet and at the end of the novel she brought the poem to the sanctuary of the oak tree as a gift to lay it to rest among the roots rising above the ground, as the old custom required. "She let her book lie unburied and dishevelled on the ground" (Orlando: 160). The plot has moved the full circle: Orlando returned where he/she belonged and the poem met its living prototype.

The Oak tree helped Orlando to find his/her true Self, understand the essence of life and mission of poetry in the face of which all vanitas vanitatum - praise and blame, money and fame - become nonsensical. She remembered the ceremony of handing her the prize and a cheque for two hundred guineas and her thoughts at that moment. "She had thought then, of the oak tree here on its hill, and what has that got to do with this, she had wondered?" (Orlando: 160).

The symbolic organization of discourses in the novel is based on combinatorial and recursive mechanisms. Various combinations of symbolic attributes and repetitions enhance the purport of the discourse and meaningfulness of the immediate contexts. Woolf's symbolism is grounded in the Tree archetype which has achieved in the novel immense symbolic potency.

\section{Conclusion}

In this article, I have attempted to analyze the Oak-tree symbolism in V. Woolf's "Orlando," its literary functions and cognitive nature. The given symbol was analyzed at two levels - conceptual and discursive.

Textually, the Oak tree performs integrating and "illuminative" functions by binding multiple episodes, motifs, and twists of the plot into an integrated whole. In addition, each episode in which the oak tree is involved is a moment of epiphany uncovering to Orlando and the reader a part of the ultimate truth drawing attention to the essence of life as V. Woolf sees it.

Though the symbol lends aesthetic sophistication to the text, its significance goes beyond stylistic beautification and gives insight into cognitive processes of symbolic conceptualizations. Based originally on a natural object, the concept developed a rich mythological and religious dimension that resulted in a complex, many-layered paradigmatic system of symbolic attributes, which at different historical periods acquired cognitive salience (prominence principle), whose value was acknowledged by society, and which became part of mental imagery, a tool for figurative thinking.

There is an intrinsic relationship between the symbol and real oak trees and their properties. Each part of the tree generates its own domain of meaningful interpretations: e.g. 'tree top' implies contact with the divine, 'roots' are anchors of stability. The Oak tree in general signifies steadfastness, immortality, recurring regeneration; its vertical form implicates ascension. Having a certain degree of conventionality, the oak tree archetype serves as cognitive substratum for V. Woolf's symbolic imagery in "Orlando." Foregrounding different facets of this complex symbol in 
various contexts, she adds new value and configurations to symbolic patterns creating her own "unfathomable cosmos" of imagery.

The in-depth reading of selected passages with the oak tree as their focal point highlights a specific symbol-oriented structure of the discourse, which centers around one or several symbolic attributes whose interplay produces representations of complex ideas important both for the plot of the novel and for V. Woolf's world view. The study showed that symbolic conceptualizations as a result of cognitive processing of objective reality in which the human imagination plays a central role can be systematically studied via literary artifacts.

\section{References}

(1985 /1939). A Sketch of the Past. New York, NY: A Harvest Book.

(2003). Orlando: A Biography. London UK: Wordsworth Classics.

Beattie, T. C. (1986). Moments of Meaning Dearly Achieved: Virginia Woolf's Sense of an Ending. Modern Fiction Studies, 32(4), 521-541. Baltimore, Maryland: Johns Hopkins University Press.https://doi.org/10.1353/mfs.0.0148

Bodkin, A. M. (1958). Archetypal Patterns in Poetry: Psychological Studies of Imagination. New York, NY: Vintage. Cambridge English Dictionary (CED). Retrieved from: https://dictionary.cambridge.org/dictionary/english/

Cirlot, J. E. (1971). A Dictionary of Symbols. London: Routledge. (2 $2^{\text {nd }}$ edition).

Cook, R. (1974).The Tree of Life. Symbol of the Center. London, UK: Thames and Hudson.

Erdész, S. (1984). The World Conception of Lajos Ámi. In A. Dundes (Ed.): Sacred Narrative: Readings in the Theory of Myth (pp. 315-335). Los Angeles, USA: University of California Press.

Frazer, J. G. (1890/1922). The Golden Bough. New York, NY: Macmillan.

Frye, N. (1952). Three Meanings of Symbolism. Yale French Studies, no. 9, 11-19. New Haven, Connecticut: Yale University Press. https://doi.org/10.2307/2929052

Frye, N. (1957). Anatomy of Criticism. Princeton, NY: Princeton University Press.https://doi.org/10.1515/9781400866908

Goethe, J. W. (1973). Werke, (vol. 12). Hamburger Ausgabe, Munich: C.H. Beck.

Guerin, W. L., Labor E., Morgan L., Reesman J., \& Willingham J. R. (2005). A Handbook of Critical Approaches to Literature. Oxford, UK: Oxford University Press.

Haberman, D. L. (2013). People Trees: Worship of Trees in Northern India. New York, NY: Oxford University Press.https://doi.org/10.1093/acprof:oso/9780199929177.001.0001

Jung, C. G. (1964). Man and his Symbols. New York, NY: Anchor Press book.

Kant, I. (1951). Critique of Judgment. New York, NY: Hafner Press.

Ladner, G. B. (1979). Medieval and Modern Understanding of Symbolism: A Comparison. Speculum, 54(2), 223-256. Chicago, Ill: The University of Chicago Press. https://doi.org/10.2307/2854972

Langacker, R. W. (1991). Concept, Image, and Symbol. The Cognitive Basis of Grammar. Berlin and New York: Mouton de Gruyter.

Langer, S. K. (1954). Philosophy In a New Key. New York, NY: The New American Library.

New International Version of the Holy Bible (NIV), 1984. Colorado Springs, CO: International Bible Society.

Online Etymology Dictionary (ED). Retrieved from: https://www.etymonline.com/

Rubin, E. (1958). Figure and ground. In D. C. Beardslee \& M. Wertheimer (Eds.) Readings in Perception (pp. 35-101). Princeton, NJ: Van Nostrand. (First published in 1915).

Skinner, Ch. M. (1911). Myths and Legends of Flowers, Trees, Fruits, and Plants. Philadelphia \& London: J.B. Lippincott Co.

Stokes, W. (1893). The Edinburgh Dinnshenchas. Folklore, 4(4), 471-496. London: Folklore Enterprises, Ltd. https://doi.org/10.1080/0015587X.1893.9720182

Struck, P. (2004). Birth of the Symbol: Ancient Readers at the Limits of Their Texts. Princeton and Oxford: Princeton University Press.https://doi.org/10.1515/9781400826094 
Thakur, N. C. (1965). The symbolism of Virginia Woolf. London UK: Oxford University Press.

White, L. A., \& Dillingham, B. (1973). The Concept of Culture (Basic Concepts in Anthropology). New York, NY: Burgess Pub. Co.

Woolf, V. (1984). The Russian Point of View. In Mrs. Dalloway and Essays. Moscow: Raduga Publishers.

Young, D. (1986). The Mythological Element in Virginia Woolf'sThe Waves: Bernard's Vision. Iowa Journal of Literary Studies, 7, 94-104. https://doi.org/10.17077/0743-2747.1195 